\title{
Phase II trial evaluating the feasibility of interdigitating folfox with chemoradiotherapy in locally advanced and metastatic rectal
} cancer

\begin{abstract}
M Michael ${ }^{*}, 1,2$, S Chander $^{3}$, J McKendrick ${ }^{4}$, J R MacKay ${ }^{5}$, M Steel ${ }^{6}$, R Hicks ${ }^{2,7}$, A Heriot ${ }^{5}$, T Leong ${ }^{3}$, P Cooray $^{4}$, M Jefford ${ }^{1,2}, \mathrm{~J}_{\text {Zalcberg }}{ }^{1}, \mathrm{M} \mathrm{Bressel}^{8}, \mathrm{~B} \mathrm{McClure}^{8}$ and S Y Ngan ${ }^{3}$

${ }^{1}$ Division of Cancer Medicine, Lower Gastrointestinal Tumour Service, Peter MacCallum Cancer Centre, Melbourne, Victoria, Australia; ${ }^{2}$ The Sir Peter MacCallum Department of Oncology, The University of Melbourne, Parkville, Melbourne, Victoria, Australia; ${ }^{3}$ Division of Radiation Oncology, Lower Gastrointestinal Tumour Service, Peter MacCallum Cancer Centre, Melbourne, Victoria, Australia; ${ }^{4}$ Department of Medical Oncology, Box Hill Hospital, Melbourne, Victoria, Australia; ${ }^{5}$ Division of Surgical Oncology, Lower Gastrointestinal Tumour Service, Peter MacCallum Cancer Centre, Melbourne, Victoria, Australia; ${ }^{6}$ Department of Surgery, Box Hill Hospital, Melbourne, Victoria, Australia; ${ }^{7}$ Cancer Imaging, Peter MacCallum Cancer Centre, Melbourne, Victoria, Australia and ${ }^{8}$ Centre for Biostatistics and Clinical Trials, Peter MacCallum Cancer Centre, Melbourne, Victoria, Australia
\end{abstract}

Background: Patients (pts) with metastatic rectal cancer and symptomatic primary, require local and systemic control. Chemotherapy used during chemoradiotherapy (CRT) is adequate for radiosensitisation, but suboptimal for systemic control. The aim of this phase II study was to assess tolerability, local/systemic benefits, of a novel regimen delivering interdigitating intensive chemotherapy with radical CRT.

Methods: Eligible pts had untreated synchronous symptomatic primary/metastatic rectal cancer. A total of 12 weeks of treatment with split-course pelvic CRT (total 50.4 Gy with concurrent oxaliplatin and 5-FU infusion) alternating with FOLFOX chemotherapy. All pts staged with CT, MRI and FDG-PET pre and post treatment.

Results: Twenty-six pts were treated. Rectal primary MRI stage: T3 81\% and T4 15\%. Liver metastases in $81 \%$. Twenty-four pts (92\%) completed the 12-week regimen. All patients received planned RT dose, and for both agents over $88 \%$ of patients achieved a relative dose intensity of $>75 \%$. Grade 3 toxicities: neutropenia 23\%, diarrhoea 15\%, and radiation skin reaction $12 \%$. Grade 4 toxicity: neutropenia 15\%. FDG-PET metabolic response rate for rectal primary $96 \%$, and for metastatic disease $60 \%$.

Conclusions: Delivery of interdigitating chemotherapy with radical CRT was feasible to treat both primary and metastatic rectal cancer. High completion and response rates were encouraging.

Patients who present with locally advanced rectal cancer (LARC) with metastatic disease present a difficult clinical challenge. These patients are usually symptomatic from their primary tumour, although co-existing distant disease will progress requiring systemic therapy. Owing to these competing elements, a common dilemma is thus whether to recommend local treatment to avoid uncontrolled pelvic disease, or commence first-line systemic chemotherapy.

Resection of the primary tumour can lead to significant postoperative complications while chemoradiotherapy (CRT), with radiosensitising infusional 5-FU, deals with the local symptoms. 
However, the 5-FU dose used is sub-therapeutic for metastatic control (O'Connell et al, 1994; Crane et al, 2001). Local therapies can also significantly delay the commencement of palliative chemotherapy, during which time the patient's condition may deteriorate, reducing their subsequent therapeutic options including metastectomy.

Systemic chemotherapy alone may provide distant disease regression, but with only short-term control of the primary, which may require subsequent salvage radiotherapy (RT). Systemic chemotherapy alone or in the neoadjuvant setting has been evaluated in this setting, with regimens such as oxaliplatin-5-FU (with or without monoclonal antibodies), achieving radiological response rates ranging from 30 to $45 \%$ (Stelzner et al, 2008; Chua et al, 2010; Suarez et al, 2011; Glynne-Jones et al, 2012).

To increase the effectiveness of RT on LARC and to optimise systemic control there have been efforts to incorporate oxaliplatin within the 5-FU-based CRT regimens, given its radiosensitisation and activity in the adjuvant/advanced disease settings. Of the five phase III trials evaluating the added benefit of oxaliplatin in preoperative CRT (Gerard et al, 2010; Aschele et al, 2011; Roh et al, 2011; Rodel et al, 2012; Schmoll et al, 2013), only two had demonstrated increased pathological response rates in favour of oxaliplatin, but with increased toxicity (Gerard et al, 2010; Rodel et al, 2012). The improved pathological response rates in favour of oxaliplatin here may reflect the lower RT dose (Gerard et al, 2010), or inadequate 5-FU backbone(Rodel et al, 2012), in the control arms of these studies. It must also be noted that in all these phase III trials, low-dose oxaliplatin was used, predominantly as a radiosensitiser, rather than delivering systemic doses. Nevertheless, lower rates of intra-abdominal metastases were discovered at surgery in patients treated with oxaliplatin (Gerard et al, 2010; Aschele et al, 2011; Rodel et al, 2012), suggesting that adding oxaliplatin may improve control of micrometastatic disease.

The reason for this lack of benefit of oxaliplatin with CRT is unclear. The added toxicity, necessitating dose reductions and treatment interruptions, may have led to undertreatment and tumour cell repopulation during treatment breaks (Martin and Bekaii-Saab, 2013). Given these issues, modified schedules of combining oxaliplatin in the treatment of LARC or LARC concurrent with metastases are warranted to optimise both local and systemic control (An et al, 2013; van Dijk et al, 2013).

In this regard, the phase II trial reported here evaluates, in patients with symptomatic LARC and metastatic disease, a novel programme of oxaliplatin-5-FU-based chemotherapy interdigitating with pelvic CRT. This protocol aims to concurrently treat both local and metastatic disease while maintaining chemotherapy dose intensity and minimising toxicity. The primary end point was the tolerability rate, defined as the percentage of patients who were able to complete (reached week 11) the planned treatment programme and who did not require a treatment break for toxicity. Secondary end points were tumour response rates of primary and metastatic disease.

\section{PATIENTS AND METHODS}

Eligibility criteria. Eligible patients met the following criteria: (1) untreated and pathologically proven rectal adenocarcinoma with distant metastasis that potentially would benefit from CRT (based on local symptoms) and systemic chemotherapy, (2) lower border of tumour $\leqslant 15 \mathrm{~cm}$ from anal verge, (3) age $\geqslant 18$ years, (4) ECOG performance status $0-2$, (5) adequate organ function (absolute neutrophil count $>1.5 \times 10^{9} 1^{-1}$, haemoglobin $>100 \mathrm{gl}^{-1}$, platelets $>100 \times 10^{9} \mathrm{l}^{-1}$, creatinine clearance $\geqslant 55 \mathrm{ml} \mathrm{min}^{-1}$, bilirubin $\leqslant 2.0 \times$ upper limit of normal (ULN), ALT $\leqslant 5 \times \mathrm{ULN})$, (6) life expectancy $\geqslant 3$ months, (7) no symptomatic peripheral neuropathy, and (8) signed informed consent.
Patients were excluded based on the following criteria: (1) prior pelvic RT, (2) febrile intercurrent illness or infection, (3) history of myocardial infarction within the previous 6 months or unstable cardiac disease or any other medical condition likely to compromise the safe treatment delivery or be potentially exacerbated by these modalities, (4) concurrent treatment with other anti-cancer therapy, (5) locally recurrent rectal cancer.

Institutional ethics review committee approval was obtained from all sites.

\section{Treatment plan}

Chemotherapy interdigitating with split-course pelvic chemoradiotherapy. The protocol therapy comprised of 12 weeks of treatment with pelvic CRT interdigitating with FOLFOX chemotherapy. The pelvic CRT consisted of $50.4 \mathrm{~Gy}, 1.8 \mathrm{~Gy}$ per fraction, 5 days per week, split into 2 equally divided courses, given with concurrent oxaliplatin plus infusional 5-FU, interdigitating with 3 courses of FOLFOX chemotherapy. The FOLFOX regimen was based on an Australian trial (Goldstein et al, 2005), and the oxaliplatin and 5-FU dose in CRT was based on a local phase I trial (Loi et al, 2005). The split-course radiation was used to reduce both the acute radiation toxicity and the impact of accelerated repopulation during RT. To maintain chemotherapy exposure during the radiation-free break, a course of chemotherapy was delivered.

The 12-week treatment programme is outlined as below (refer to Figure 1):

Weeks 1-2: 1 cycle FOLFOX chemotherapy (oxaliplatin $100 \mathrm{mg} \mathrm{m}^{-2}$ per $2 \mathrm{~h}$, leucovorin $200 \mathrm{mg} \mathrm{m}^{-2}$ per $2 \mathrm{~h}$, then 5 -FU $400 \mathrm{mg} \mathrm{m}^{-2}$ bolus day 1 , then 5 -FU continuous infusion (CI) $2.4 \mathrm{~g} \mathrm{~m}^{-2}$ per $46 \mathrm{~h}$.

Weeks 3-5: pelvic RT 25.2 Gy/1.8 Gy fractions for 5 days in each of weeks 3 and 4 and for 4 days in week 5 ; with $85 \mathrm{mg} \mathrm{m}^{-2}$ oxaliplatin day 1 week 3 , plus 5 -FU CI $200 \mathrm{mg} \mathrm{m}^{-2}$ per day on the days of RT (Monday to Friday).

Weeks 6-7: FOLFOX chemotherapy, as above, day 1, week 6.

Weeks 8-10: pelvic RT as above for 5 days in each of weeks 8 and 9 and for 4 days in week $10 ; 85 \mathrm{mg} \mathrm{m}^{-2}$ oxaliplatin day 1 week 8 , plus 5 -FU CI $200 \mathrm{mg} \mathrm{m}^{-2}$ per day on the days of RT (Monday to Friday).

Weeks 11-12: FOLFOX chemotherapy, as above, on day 1, week 11.

Radiation technique. The pelvic CRT consisted of 50.4 Gy, 1.8 Gy per fraction, 5 days per week, split into 2 equally divided courses. The radiation clinical target volume (CTV) for the first $45 \mathrm{~Gy}$ included the primary rectal cancer, perirectal and internal iliac nodes, mesorectum, pelvic side walls and presacral space, with the upper border at the sacral promontory. The CTV was reduced after $45 \mathrm{~Gy}$ to include gross disease with a $1-\mathrm{cm}$ margin. Megavoltage RT $(6-18 \mathrm{MeV})$ and multiple field techniques (3 fields: PA +2 laterals, or 4 fields) were used. All fields were treated daily. Port films were performed weekly. Belly-board and customised

\begin{tabular}{|c|c|c|c|c|c|c|c|c|c|c|c|c|}
\hline Weeks & 1 & 2 & 3 & 4 & 5 & 6 & 7 & 8 & 9 & 10 & 11 & 12 \\
\hline RT & & & $5 \mathrm{fr}^{\mathrm{a}}$ & $5 \mathrm{fr}$ & $4 \mathrm{fr}$ & & & $5 \mathrm{fr}$ & $5 \mathrm{fr}$ & $4 \mathrm{fr}$ & & \\
\hline Chemo & FOLFOX & \multicolumn{2}{|c|}{ Ox-5FU+RTc } & FOLFOX & \multicolumn{2}{|c|}{ Ox-5FU+RT } & FOLFOX \\
& & & & & & & & &
\end{tabular}

a fr: Radiation fraction

b FOLFOX chemotherapy: oxaliplatin $100 \mathrm{mg} \mathrm{m}^{-2}$ per 2 hours, leucovorin $200 \mathrm{mg} \mathrm{m}^{-2}$ per 2 hours, then 5 -FU $400 \mathrm{mg} \mathrm{m}^{-2}$ bolus day 1 , then 5 -FU continuous infusion $(\mathrm{Cl}) 2.4 \mathrm{~g} \mathrm{~m}^{-2}$ per 46 hours, weeks 1,6 , and 11

c Ox-5FU+RT: Oxaliplatin $85 \mathrm{mg} \mathrm{m}^{-2}$ day $1,5 \mathrm{FU} \mathrm{Cl}, 200 \mathrm{mg} \mathrm{m}^{-2}$ per day on days of pelvic RT, weeks 3-5, and 8-10.

Figure 1. Treatment schema. 
shielding were used to minimise toxicity. Treatment planning was performed with computerised dosimetry. ICRU-50 and ICRU-62 were followed. Verification images were performed weekly.

Treatment modification during chemotherapy interdigitating with split-course pelvic chemoradiotherapy. For the commencement of each course of FOLFOX and during CRT, on day 1 of weeks 3 and 8 of chemotherapy with oxaliplatin +5 -FU CI, patients were required to have: ANC $>1.5 \times 10^{9} 1^{-1}$ and platelets $>100 \times 10^{9} 1^{-1}$ and had recovered from treatment-related nonhaematological toxicities to grade $0-2$. During CRT, on day 1 of weeks $4,5,9$ and 10 of chemotherapy with 5-FU CI only, patients were required to have $\mathrm{ANC} \geqslant 1.0 \times 10^{9} 1^{-1}$ and platelets $\geqslant 100 \times 10^{9} 1^{-1}$.

Chemotherapy dose reductions/omissions were made based on haematological and non-haematological toxicities. Chemotherapy was withheld for grade 3 or 4 clinically significant treatmentrelated non-haematological toxicities and recommenced with a dose reduction once there had been recovery to grade $0-2$. Radiotherapy, together with chemotherapy, was suspended if the patient experienced treatment-related grade 3 or 4 radiationassociated toxicities. If recovery of toxicity to grade 2 or less had not occurred after 2 weeks of delay, treatment was ceased.

As the primary end point was feasibility, treatment was not to be delayed due to toxicity, rather the relevant agent was omitted until the adverse event had resolved, followed by subsequent dose modification. Omitted treatment was not made up for and thus all treatment was completed within the planned 12 weeks.

\section{Patient evaluations}

Pre-treatment evaluation: Within 4 weeks of trial entry, patients underwent clinical evaluation (history, physical examination, ECOG performance status assessment, neurological examination) as well as digital rectal examination, sigmoidoscopy and tumour biopsy. Blood samples were taken for full-blood examination, biochemistry (urea and electrolytes, liver function tests (ALP, ALT, serum bilirubin) and carcinoembyronic antigen levels). Baseline staging was via CT scan chest, abdomen and pelvis, MRI pelvis, and FDG-PET scan.

Evaluations during treatment: Before each dose of FOLFOX and weekly during CRT (weeks 1, 3, 6, 8 and 11) patients underwent clinical evaluation (as above), toxicity assessment and blood examination as above.

Evaluations following completion of therapy: Patients underwent clinical evaluation (as above), toxicity assessment and were restaged with CT scan of chest, abdomen and pelvis, FDG-PET and pelvic MRI.

\section{Statistical analysis}

\section{Prospectively defined end points}

Primary end point: The tolerability rate was defined as the percentage of patients who were able to complete (reached week 11) the planned treatment programme and who did not require a treatment break for toxicity. Secondary tolerability end points were: (1) actual dose intensity ( $\mathrm{mg} \mathrm{m}^{-2}$ per week): the total dose per body surface area divided by the duration of drug treatment (the number of weeks between start and finish of chemotherapy plus 14 days); (2) relative dose intensity (\%): the ratio of the actual dose intensity to the planned dose intensity. The planned dose intensity being defined as being equal to $100 \%$; (3) relative treatment duration: the ratio of the actual duration of treatment to the planned duration of treatment.
Secondary end points: Toxicity rates were graded using the NCI Common Terminology Criteria for Adverse Events v3.0 (CTCAE, 12 December 2003, http://ctep.cancer.gov/forms/CTCAEv3.pdf). Anatomical response (including pelvic and distant disease response rates were measured separately by CT/MRI, assessed using RECIST 1.0 criteria (Therasse et al, 2000), and by PET criteria at baseline and at 16 weeks. The PET metabolic response was assessed by two methods: (1) based on standardised uptake value (SUV) assessment according to the recommendations of the EORTC PET Study Group (Young et al, 1999). A SUV metabolic response in a lesion was defined as either a complete or partial metabolic response (CMR or a PMR) (2) and qualitatively or visually as previously described (Hicks, 2005). A visual metabolic response in a lesion was defined as either a CMRV or a PMRV. Both criteria were based on baseline and 16-week studies displayed side by side with normalised liver uptake.

Continuous variables were summarised using median and range. Qualitative variables were summarised by means of counts and percentages. All the confidence intervals were exact $95 \%$ confidence intervals.

Post hoc analysis of surgery post completion of planned therapy. The trial protocol ended 4 weeks after completion of the planned treatment programme. Thus the trial's prospectively defined end points (described above) had not included data collection with regard to the number of patients who underwent resection of their primary and metastectomy. These data were thus extracted from a retrospective review of the patients' records.

\section{RESULTS}

Patient cohort. Overall, $\sim 40 \%$ of all rectal cancer patients referred to both centres were elligible for this trial and $85 \%$ percent of these were enrolled. The patients demographics are summarised in Table 1. Overall, there were 26 patients recruited. The majority had MRI-staged T3 rectal cancer (81\%), and within $10 \mathrm{~cm}$ from the anal verge (85\%). All patients had metastatic disease. Hepatic metastases were present in $81 \%$ (46\% alone).

\section{Treatment tolerability}

Radiation therapy. All patients received the planned dose of $50.4 \mathrm{~Gy}$; however, 25 (96\%) received as specified in the protocol. In the remaining patient, the concurrent infusional 5-FU was ceased during week 4 due to grade 2 chest pain, possibly ischaemic. Chemotherapy was ceased and RT continued at $5 \times 1.8 \mathrm{~Gy}$ per week until 50.4 Gy per 28 fractions.

Chemotherapy. The chemotherapy delivery parameters are summarised in Table 2. As described above, there was no protocol allowance for treatment to be delayed due to toxicity. The relevant agent was omitted, until the adverse events had resolved, followed by subsequent dose modification.

Overall, 16 or $62 \%$ of the cohort had completed the planned therapy duration (i.e., 11 weeks) without a chemotherapy dose interruption. Hence 10 of the 26 patients $(38 \%)$ had a chemotherapy omission at different phases of treatment: in week 3 (the commencement of first block CRT), by grade 1 $(n=1)$ and grade 4 neutropenia $(n=1)$; in week 6 (post first block of CRT), due to grade 1 thrombocytopenia $(n=1)$; in week 8 (the commencement of the second block of CRT) due to grade $3(n=4)$ and grade 4 neutropenia $(n=2)$ and grade 2 thrombocytopenia $(n=1)$; in week 10 (last week of second block of CRT) by grade 2 thrombocytopenia and malignancyrelated pulmonary embolism $(n=1)$; and in week 11 due to grade 1 fever resulting in hosptial admission $(n=1)$. Overall, 


\begin{tabular}{|c|c|c|}
\hline Parameter & $n$ & $\%(95 \% \mathrm{Cl})$ \\
\hline \multicolumn{3}{|l|}{ Gender } \\
\hline $\begin{array}{l}\text { Male } \\
\text { Female }\end{array}$ & $\begin{array}{r}18 \\
8\end{array}$ & $\begin{array}{l}69(48-86) \\
31(14-52)\end{array}$ \\
\hline \multicolumn{3}{|l|}{ Age } \\
\hline \multicolumn{3}{|l|}{$\begin{array}{l}\text { Mean }=61 \text { years } \\
\text { Range }=33 \text { and } 82 \text { years }\end{array}$} \\
\hline \multicolumn{3}{|l|}{$\mathrm{T}$ stage } \\
\hline $\begin{array}{l}\text { T2 } \\
\text { T3 } \\
\text { T4 }\end{array}$ & $\begin{array}{r}1 \\
21 \\
4\end{array}$ & $\begin{array}{c}4(0-20) \\
81(61-93) \\
15(4-35)\end{array}$ \\
\hline \multicolumn{3}{|l|}{$\mathbf{N}$ stage } \\
\hline $\begin{array}{l}\text { Stage } 0 \\
\text { Stage } 1 \\
\text { Stage } 2\end{array}$ & $\begin{array}{r}2 \\
10 \\
14\end{array}$ & $\begin{array}{c}8(1-25) \\
38(20-59) \\
54(33-73)\end{array}$ \\
\hline
\end{tabular}

Distance of the lower border of the tumour from the anal verge

\begin{tabular}{|l|r|l|}
\hline $0-5 \mathrm{~cm}$ & 7 & $27(12-48)$ \\
$6-10 \mathrm{~cm}$ & 15 & $58(37-77)$ \\
$11 \mathrm{~cm}$ or more & 4 & $15(4-35)$
\end{tabular}

\section{Site of metastasis}

\begin{tabular}{|l|r|c|}
\hline Liver only & 12 & $46(27-67)$ \\
Extra-pelvic lymph node and lung & 1 & $4(0-20)$ \\
Lung only & 1 & $4(0-20)$ \\
Liver and extra-pelvic lymph node & 2 & $8(1-25)$ \\
Liver and lung & 7 & $27(12-48)$ \\
Extra-pelvic lymph node only & 3 & $12(2-30)$ \\
Liver overall & 21 & $81(61-93)$ \\
Extra-pelvic lymph node overall & 6 & $23(9-44)$ \\
Lung overall & 9 & $35(17-56)$
\end{tabular}

\section{Serum hepatic biochemistries}

Bilirubin (median, range) $\left(\mu \mathrm{moll} \mathrm{I}^{-1}\right)$

ALP (median, range) $\left(U I^{-1}\right)$

ALT (Median, Range) $\left(\mathrm{UI}^{-1}\right)$

$8(4-38)$

$88(60-774)$

$18(6-110)$

\section{Carcinoembryonic antigen (CEA)}

\begin{tabular}{|l|c|}
\hline Median & 24.55 \\
Range & $(1.7-922.7)$ \\
\hline
\end{tabular}

Abbreviations: $\mathrm{ALP}=$ alkaline phosphatase; $\mathrm{ALT}=$ alanine transaminase $; \mathrm{Cl}=$ confidence interval.

only two patients had two dose ommisions due to myelosuppression.

The proportion of patients who achieved the planned dose intensity for oxaliplatin and 5-FU was 54\% (95\% CI (33-73\%)) and $58 \%(95 \%$ CI $(37-77 \%))$, respectively (Table 2). It must be noted that for both agents, over $88 \%$ of patients achieved a relative dose intensity of $>75 \%$. In terms of the primary end point (i.e., tolerability rate defined as the percentage of patients that completed the planned treatment programme), 24 of the 26 patients reached week 11 of the treatment, which corresponds to $92 \%$ of the cohort (95\% CI (75-99\%)).

Toxicity. Table 3 summarises the number of patients experiencing a grade 3 or higher toxicity related to treatment. Table 4 summarises all treatment-related adverse events experienced at
Table 2. Chemotherapy dose-delivery details $(n=26)$

\begin{tabular}{|c|c|c|}
\hline Parameter & $n$ & $\%(95 \% \mathrm{Cl})$ \\
\hline \multicolumn{3}{|l|}{ Oxaliplatin } \\
\hline $\begin{array}{l}\text { Oxaliplatin with dose intensity as planned } \\
\left(\mathrm{mg} \mathrm{m}^{-2} \text { per week) }\right.\end{array}$ & 14 & $54(33-73)$ \\
\hline Oxaliplatin with relative dose intensity $\geqslant 0.75$ & 23 & 88 (70-98) \\
\hline \multicolumn{3}{|l|}{ Leucovorin } \\
\hline $\begin{array}{l}\text { Leucovorin with dose intensity as planned } \\
\text { (mg m }{ }^{-2} \text { per week) }\end{array}$ & 18 & $69(48-86)$ \\
\hline \multicolumn{3}{|l|}{ 5-FU } \\
\hline $\begin{array}{l}\text { 5-FU with dose intensity as planned } \\
\left(\mathrm{mg} \mathrm{m}^{-2} \text { per week) }\right.\end{array}$ & 15 & $58(37-77)$ \\
\hline 5 -FU with relative dose intensity $\geqslant 0.75$ & 24 & $92(75-99)$ \\
\hline \multicolumn{3}{|l|}{ Treatment delivery } \\
\hline Treatment delay due to toxicity $^{a}$ & 3 & $12(2-30)$ \\
\hline Treatment dose omitted & 10 & $38(20-59)$ \\
\hline \multicolumn{3}{|c|}{$\begin{array}{l}\text { Abbreviations: } \mathrm{Cl}=\text { confidence interval; } 5-\mathrm{FU}=5 \text {-fluorouracil. } \\
\text { a }_{\text {There was no provision in the protocol for treatment to be delayed due to toxicity, rather }} \\
\text { the relevant agent was to be omitted until the adverse events were overcome, with } \\
\text { subsequent dose modification. However, on three occasions there were protocol deviations } \\
\text { involving treatment delay, refer to Results. }\end{array}$} \\
\hline
\end{tabular}

least once by patients. The most common adverse events experienced were diarrhoea, fatigue, sensory neuropathy and neutropenia.

Overall, 19 (73\%) of the 26 patients had at least one grade 3 or more toxicity. The most frequent grade $3+$ toxicity was neutropenia: 6 patients (23\%) with grade 3 and 4 patients (15\%) with grade 4 . There were no episodes of febrile neutropenia.

Overall radiation-induced skin reaction and diarrhoea were limited to grade 3 (12\% and $15 \%$, respectively) and radiationinduced procticits was limited to grade 2 (8 episodes). Fatigue and neuropathy were also common, but only grade 3 in 2 patients and 1 patient respectively.

\section{Radiological and functional imaging responses}

Primary disease response. The radological and functional imaging response is summarised in Table 5. Primary tumoural response was assessed in all 26 patients by FDG-PET and in 25 by MRI. No patients had a radiological (MRI) CR in the primary, however, $72 \%$ had a radiological PR. In terms of FDG-PET metabolic response, $31 \%$ (8 out of 26 ) had a CMRv. Overall, only one patient did not have at least a partial metabolic response in the primary according to either SUV or visual metabolic response criteria.

Metastatic disease response. The response in metastatic lesions was evaluated in 25 patients by FDG and in 23 by CT scan. Three patients had non-evaluable disease at baseline hence not enabling response assessment using RECIST criteria. Response rates in metastatic lesions were $48 \%$ by CT criteria, $52 \%$ by visual metabolic response (CMRv 24\%) and $60 \%$ by SUV metabolic response (CMR 16\%) criteria.

Surgery post completion of planned therapy. On post hoc review of patient records: overall 6 of the 24 patients entered into the trial, underwent rectal surgery post completion of the planned treatment programme, either for palliation to optimise local control $(n=4)$ or in a curative setting $(n=2)$. Of the 6,3 underwent abdominalperineal resection and the other 3 anterior resections. All patients 
Table 3. Details of patients who experienced a grade 3 or higher toxicity related to treatment

\begin{tabular}{|l|r|c|}
\hline Parameter $^{\text {a }}$ & $n$ & $\%(\mathbf{n = 2 6 )}$ \\
\hline Laboratory & 1 & 4 \\
\hline Haemoglobin & 6 & 23 \\
White cell count & 10 & 38 \\
Neutrophils & 1 & 4 \\
ALP &
\end{tabular}

Gastrointestinal

\begin{tabular}{|l|r|r|}
\hline Haemorrhage, rectum & 1 & 4 \\
Diarrhoea & 4 & 15 \\
Pain - anorectal & 3 & 12 \\
Pain - rectum & 2 & 8 \\
Rash/desquamation/radiation dermatitis & 4 & 16
\end{tabular}

\begin{tabular}{|l|l|l|}
\hline General & 1 & 4 \\
\hline Neuropathy: sensory & 1 & 4 \\
Dizziness & 2 & 8 \\
Fatigue & 1 & 4 \\
Vomiting & 1 & 4 \\
Nausea & 1 & 4 \\
Pneumonia & 1 & 4 \\
Thrombosis/thrombus/embolism &
\end{tabular}

At least one grade 3 toxicity

Abbreviations: $\mathrm{ALP}=$ alkaline phosphatase $\mathrm{CTCAE}=$ Common Terminology Criteria for Adverse Events.

${ }^{\mathrm{a}}$ CTCAE V3.0 adverse event term.

had evidence of pathological treatment response in the resected rectal primary, including 1 patient with a complete pathological response and 2 patients with only residual isolated tumour cells in the resected specimen. Two patients (including the 1 patient who achieved a complete pathological response in the resected primary) underwent simultaneous or sequential liver metastectomy, respectively.

Of the 6 patients who underwent tumoural resection, 2 are still alive without evidence of disease $\sim 5$ years post surgery.

\section{DISCUSSION}

Patients with metastatic rectal cancer with a locally advanced primary in situ represent a complex oncological problem. The standard approaches to deal with local symptoms provide inadequate systemic exposure for distant disease control. Novel regimens concurrently addressing both local and systemic disease are urgently warranted.

In this regard, the phase II trial reported here evaluated a novel programme of oxaliplatin-5-FU interdigitating with pelvic CRT to concurrently address both local and distant disease. The split-course CRT, with chemotherapy in the RT-free windows, as evaluted here, theorectically achieves several aims. First, it reduces the extent of accelerated repopulation induced after the first 2 weeks of standard fractionated long-course RT (Tarnawski et al, 2002). Second, shorter intensive CRT regimens are associated with reducued toxicity and greater probability of local control (Ritter, 1999). Finally, the chemotherapy in the RT-free windows can potentially be delivered at full systemic doses to provide continued control of metastatic disease. The utility of split-course RT in rectal cancer has
Table 4. All related adverse events (CTCAE V3.0) experienced at least once by patients

\begin{tabular}{|c|c|c|c|c|c|}
\hline & \multicolumn{4}{|c|}{ CTC grade events } & \multirow[b]{2}{*}{$\begin{array}{c}\text { No. of } \\
\text { patients } \\
\text { experiencing } \\
\text { any grade } \\
\text { toxicity }\end{array}$} \\
\hline Adverse event ${ }^{a}$ & 1 & 2 & 3 & 4 & \\
\hline \multicolumn{6}{|l|}{ Laboratory } \\
\hline Haemoglobin & 19 & 3 & 1 & 0 & 19 \\
\hline WCC & 19 & 12 & 6 & 0 & 21 \\
\hline Neutrophils & 14 & 9 & 7 & 4 & 17 \\
\hline Platelets & 15 & 2 & 0 & 0 & 15 \\
\hline ALP & 6 & 2 & 1 & 0 & 6 \\
\hline ALT & 13 & 3 & 0 & 0 & 13 \\
\hline Bilirubin & 3 & 1 & 0 & 0 & 4 \\
\hline
\end{tabular}

\section{Gastrointestinal}

Anorexia

Constipation

Diarrhoea

Haemorrhage, GI - rectum

Mucositis/stomatitis

Nausea

Pain - anus

Pain - perineum

Pain - rectum

Proctitis

Vomiting

\begin{tabular}{|r|r|l|l|r|}
2 & 1 & 0 & 0 & 2 \\
7 & 3 & 0 & 0 & 9 \\
19 & 10 & 4 & 0 & 21 \\
2 & 0 & 1 & 0 & 3 \\
11 & 2 & 0 & 0 & 12 \\
19 & 5 & 1 & 0 & 19 \\
3 & 1 & 1 & 0 & 4 \\
2 & 0 & 0 & 0 & 2 \\
5 & 1 & 2 & 0 & 7 \\
14 & 8 & 0 & 0 & 15 \\
8 & 3 & 1 & 0 & 9
\end{tabular}

\section{General}

\section{Confusion}

Cystitis

Dizziness

Dysuria

Fatigue

Fever (non-neutropenic)

Alopecia

Incontinence, urinary

Infection: pneumonia

Infection: genito-urinary tract

Neurology - oral-laryngo-

pharayngeal dysesthesia

Neuropathy: motor

Neuropathy: sensory

Neuralgia/peripheral nerve

Pain - bladder

Rash/desquamation

Radiation dermatitis

Rash: hand-foot skin reaction

Taste alteration (dysgeusia)

Thrombo-embolism

Urinary frequency/urgency

Urinary retention

Voice changes/dysarthria

Weight loss

\begin{tabular}{|c|c|c|c|c|}
\hline 0 & 0 & 1 & 0 & 1 \\
\hline 2 & 1 & 0 & 0 & 2 \\
\hline 4 & 0 & 1 & 0 & 5 \\
\hline 2 & 0 & 0 & 0 & 2 \\
\hline 20 & 11 & 2 & 0 & 22 \\
\hline 4 & 0 & 0 & 0 & 4 \\
\hline 4 & 0 & 0 & 0 & 4 \\
\hline 0 & 1 & 0 & 0 & 1 \\
\hline 0 & 0 & 1 & 0 & 1 \\
\hline 0 & 2 & 0 & 0 & 2 \\
\hline 5 & 2 & 0 & 0 & 7 \\
\hline 0 & 1 & 0 & 0 & 1 \\
\hline 24 & 4 & 1 & 0 & 24 \\
\hline 1 & 0 & 0 & 0 & 1 \\
\hline 8 & 0 & 0 & 0 & 8 \\
\hline 5 & 0 & 1 & 0 & 5 \\
\hline 12 & 4 & 3 & 0 & 12 \\
\hline 2 & 1 & 0 & 0 & 3 \\
\hline 8 & 0 & 0 & 0 & 8 \\
\hline 0 & 0 & 1 & 0 & 1 \\
\hline 9 & 5 & 0 & 0 & 10 \\
\hline 1 & 1 & 0 & 0 & 2 \\
\hline 2 & 0 & 0 & 0 & 2 \\
\hline 1 & 0 & 0 & 0 & 1 \\
\hline
\end{tabular}

Abbreviations: $A L P=$ alkaline phosphatase; $A L T=$ alanine transaminase; $C T C=C o m m o n$ Terminology Criteria; $\mathrm{GI}=$ gastrointestinal; $\mathrm{WCC}=$ white cell count.

${ }^{\mathrm{a}}$ CTCAE V3.0 adverse event term.

not been reported, and thus it is unclear whether such an approach is associated with a negative impact on outcome in terms of local control or survival. There are several examples in other cancer 


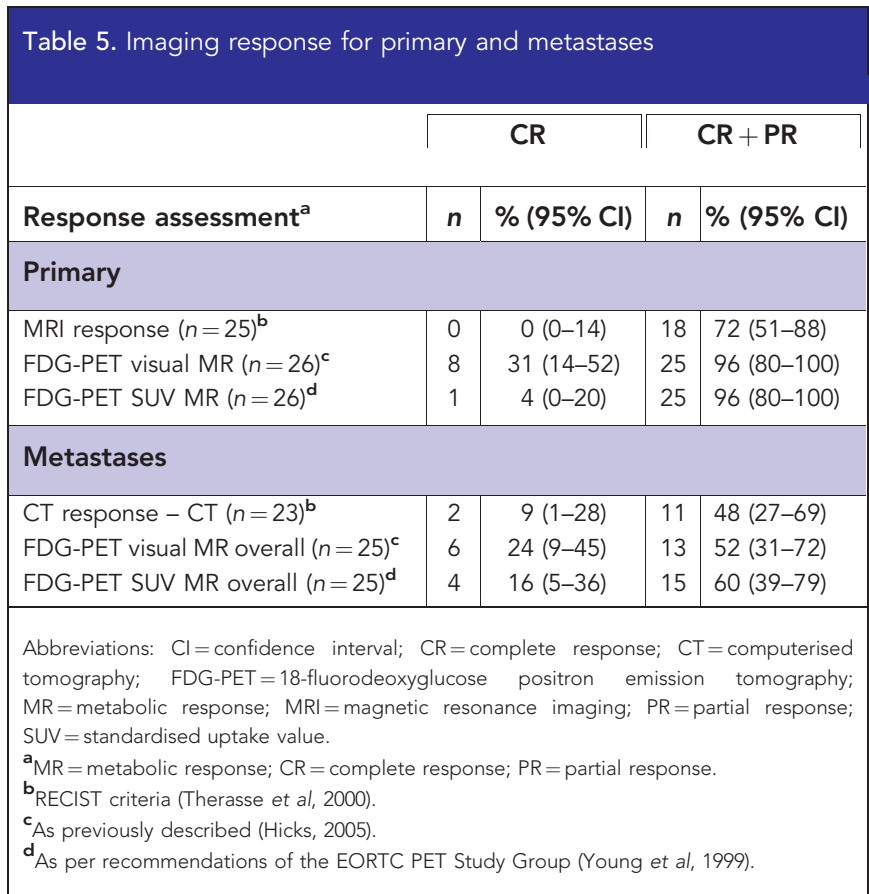

types, associated with reduced toxicity while maintaining efficacy (Pradier et al, 2004; Metcalfe et al, 2010; Fukuda et al, 2012; Gogna et al, 2012). The high metabolic response rates of the primary rectal cancer reported here support that this strategy warrants further study, but it should also be noted that split-course radiation was reported to have a negative impact in head and neck (Daoud et al, 2007; Miszczyk et al, 2014), gynaecological (Pedersen et al, 1994), and anal cancers (John et al, 1996).

The primary end point of the trial reported here was tolerability rate: defined as the percentage of patients who completed (reached week 11) the planned treatment programme and who did not require a treatment break for toxicity. Overall, 24 (92\%) of the 26 patients reached week 11 of the treatment. As well, $88 \%$ of patients achieved a relative chemotherapy dose intensity of $>75 \%$ (Table 2). All patients received the planned radiation dose, whereas 10 patients (38\%) had at least one chemotherapy treatment omission, the majority for myelosuppression. The chemotherapy dose intensity achieved was a function of the prospectively defined haematologcial parameter thresholds for the commencement of systemic therpay both as a single modality or in combination with RT. The thresholds represented our institutional practices and are similar to those used in the phase I trial of oxaliplatin and infusional 5-FU, with pelvic RT reported from our centre (Loi et al, 2005).

A direct comparison of the dose delivery and toxicities with this regimen relative to the other reported oxaliplatin-based CRT regimens is difficult for several reasons including: (i) the use of a split course of oxaliplatin-5-FU CRT, (ii) the impact of full-dose FOLFOX given before the start of CRT and in the RT-free window, and (iii) the modest cohort size. With these caveats, it appears that the achieved dose intensity was similar to that in the reported phase III trials. In the STAR-01 phase III trial $(n=747)$, patients with resectable LARC were randomised to pelvic radiation $(50.4 \mathrm{~Gy}$ per 28 fractions) with infusional 5 -FU ( $225 \mathrm{mg} \mathrm{m}^{-2}$ per day) either alone or with oxaliplatin $\left(60 \mathrm{mg} \mathrm{m}^{-2}\right.$ per week $\left.6 \times\right)$ (Aschele et al, 2011 ). Overall, $66 \%$ of patients in the oxaliplatin arm recieved all six weekly doses, and $75 \%$ had a delivered/planned dose ratio of $\geqslant 80 \%$ (Aschele et al, 2011). The phase III CAO/ARO/AIO-04 trial randomised patients with resectable LAR to 5-FU-based CRT (50.4 Gy plus infusional 5-FU $1000 \mathrm{mg} \mathrm{m}^{-2}$, days $1-5$ and 29-33), $v s$ the same RT with infusional 5-FU (250 $\mathrm{mg} \mathrm{m}^{-2}$ days $1-14$ and 22-35) and oxaliplatin $\left(50 \mathrm{mg} \mathrm{m}^{-2}\right.$ per week $\left.4 \times\right)$. During the CRT, $85 \%$ of the 606 patients in the oxaliplatin-5-FU CRT arm had full-dose chemotherapy, and $94 \%$ had the full-dose RT (Rodel et al, 2012).

In this trial, the most frequent toxicity was neutropenia: 4 patients (15\%) had grade 4 neutropenia but without febrile neutropenia. Overall, there was no grade 4 non-haematologcial toxicity and $<15 \%$ of patients had grade 3 radiation-induced skin reaction, or grade 3 diarrhoea (Table 5). The STAR-01 phase III trial, observed in the oxaliplatin arm 15\% grade 3 diarrhoea and with $5 \%$ grade $3 / 4$ radiation dermatitis (Aschele et al, 2011). In the phase III CAO/ARO/AIO-04 trial, grade 3-4 diarrhoea was observed in $12 \%$ of patients treated with oxaliplatin-5-FU CRT (Rodel et al, 2012). These observations were supported by a smaller phase II trial of CRT using oxaliplatin $60 \mathrm{mg} \mathrm{m}^{-2}$ per week and 5 -FU $\left(200 \mathrm{mg} \mathrm{m}^{-2}\right.$ per day over five days $\left.5 \times\right)$, combined with 45 Gy per 25 fractions (Fontana et al, 2013).

In this trial, only 6 of the 24 patients had undergone resection of their rectal cancer and/or metastases (Results section), hence pathological response data are very limited to generate any firm conclusions. However, the imaging response rates for both the primary and metastatic disease with this intensive novel regimen reported here was promising. The overall radiologcial (MRI) response rate for the primary was $72 \%$. There are limited and inconsistent data regarding the value of rectal MRI for restaging post CRT and hence is not considered a routine procedure. The interpretation of the post-CRT MRI tumour signal needs to distinguish between fibrosis and residual-treated tumour (Patel et al, 2012a,b). A recent meta-analysis evaluated 33 studies ( $n=1556$ patients) to obtain performance values of restaging MRI for LARC post neoadjuvant treatment. For tumour stage, the mean sensitivity was $50.4 \%$, and the mean specificity $91.2 \%$ (van der Paardt et al, 2013). In one multicentre prospective database study, 285 patients had restaging MRI and CT post CRT. MRI could not predict $\mathrm{T}$ stage $($ kappa $=0.212)$ or nodal involvement $($ kappa $=0.336)$. Most pertinently, MR imaging was unable to detect a complete pathological response (kappa =0.021) (Hanly et al, 2013).

The primary rectal (complete or partial metabolic) FDG-PET response was $96 \%$ (either visual or SUV), with $31 \%$ having a CMRv. A retrospective study from our centre $(n=78)$ had evaluated the value of FDG-PET response post CRT using a 5-FU-based neoadjuvant therapy (Yeung et al, 2011). Post CRT, $47 \%$ of patients had a CMR, $33 \%$ a PMR, however, only $5 \%$ had a complete pathological response. Despite this, PET metabolic response was strongly predictive of survival (Yeung et al, 2011). In the phase I trial of oxaliplatin-5-FU-based pelvic CRT from our centre described above, FDG-PET showed metabolic responses in 11 of the 12 primary tumours assessed (Loi et al, 2005).

In the trial reported here, the overall radiological response for the metastastic disease was $48 \%$, whereas the overall PET metabolic response rate was $60 \%$ (CR rate $16 \%$ ). The overall radiological response rate was similar to the published literature for the FOLFOX regimen in metastatic colorectal cancer, where rates of $\sim 50 \%$ have been reported (de Gramont et al, 2000; Cassidy et al, 2004; Goldstein et al, 2005). It must be noted that the structural and functional imaging results observed in the trial reported here are preliminary and are not reinforced by pathological response data or disease control parameters (local recurrence, disease-free survival, etc).

We have thus demonstrated that this novel regimen of splitcourse CRT with concurrent oxaliplatin-5-FU and FOLFOX chemotherapy in the RT-free window is tolerable, deliverable and has demonstrated promising structural and functional imaging response rates for both primary and metastatic disease. There are several ways of optimising the regimen further to increase the control of the systemic disease while maintaining local control, including the utility of initial induction chemotherapy prior to CRT (Shin et al, 2011; Cercek et al, 2013; Fernandez-Martos et al, 
2014), the utility of an irinotecan-5-FU backbone (Glynne-Jones et al, 2007; Nakamura et al, 2014), or biological agents (Crane et al, 2010; Gasparini et al, 2012; van Dijk et al, 2013). The regimen reported here is now being evaluated with the addition of bevacizumab and in patients with locally advanced disease without metastases (TROG 0901).

\section{ACKNOWLEDGEMENTS}

Sanofi Australia Pty Ltd. provided research funding for this study.

\section{CONFLICT OF INTEREST}

The authors declare no conflict of interest.

\section{REFERENCES}

An X, Lin X, Wang FH, Goodman K, Cai PQ, Kong LH, Fang YJ, Gao YH, Lin JZ, Wan DS, Pan ZZ, Ding PR (2013) Short term results of neoadjuvant chemoradiotherapy with fluoropyrimidine alone or in combination with oxaliplatin in locally advanced rectal cancer: a meta analysis. Eur J Cancer 49(4): 843-851.

Aschele C, Cionini L, Lonardi S, Pinto C, Cordio S, Rosati G, Artale S, Tagliagambe A, Ambrosini G, Rosetti P, Bonetti A, Negru ME, Tronconi MC, Luppi G, Silvano G, Corsi DC, Bochicchio AM, Chiaulon G, Gallo M, Boni L (2011) Primary tumor response to preoperative chemoradiation with or without oxaliplatin in locally advanced rectal cancer: pathologic results of the STAR-01 randomized phase III trial. J Clin Oncol 29(20): 2773-2780.

Cassidy J, Tabernero J, Twelves C, Brunet R, Butts C, Conroy T, Debraud F, Figer A, Grossmann J, Sawada N, Schoffski P, Sobrero A, Van Cutsem E, Diaz-Rubio E (2004) XELOX (capecitabine plus oxaliplatin): active first-line therapy for patients with metastatic colorectal cancer. J Clin Oncol 22(11): 2084-2091.

Cercek A, Goodman K, Hajj C, Weisberger E, Segal N, Reidy D, Stadler Z, Wu A, Weiser M, Paty P, Guillem J, Nash G, Temple J, Garcia-Aguilar J, Saltz LB (2013) Chemotherapy first, followed by chemoradiation (CRT) and then surgery, in the management of locally advanced rectal cancer (LARC). J Clin Oncol 31: abstr 3605.

Chua YJ, Barbachano Y, Cunningham D, Oates JR, Brown G, Wotherspoon A, Tait D, Massey A, Tebbutt NC, Chau I (2010) Neoadjuvant capecitabine and oxaliplatin before chemoradiotherapy and total mesorectal excision in MRI-defined poor-risk rectal cancer: a phase 2 trial. Lancet Oncol 11(3): 241-248.

Crane CH, Eng C, Feig BW, Das P, Skibber JM, Chang GJ, Wolff RA, Krishnan S, Hamilton S, Janjan NA, Maru DM, Ellis LM, Rodriguez-Bigas MA (2010) Phase II trial of neoadjuvant bevacizumab, capecitabine, and radiotherapy for locally advanced rectal cancer. Int J Radiat Oncol Biol Phys 76(3): $824-830$.

Crane CH, Janjan NA, Abbruzzese JL, Curley S, Vauthey J, Sawaf HB, Dubrow R, Allen P, Ellis LM, Hoff P, Wolff RA, Lenzi R, Brown TD, Lynch P, Cleary K, Rich TA, Skibber J (2001) Effective pelvic symptom control using initial chemoradiation without colostomy in metastatic rectal cancer. Int J Radiat Oncol Biol Phys 49(1): 107-116.

Daoud J, Toumi N, Siala W, Ghorbel A, Drira MM, Frikha M (2007) Results of a prospective randomised trial comparing conventional radiotherapy to split course bifractionated radiation therapy in patients with nasopharyngeal carcinoma. Radiother Oncol 85(1): 17-23.

de Gramont A, Figer A, Seymour M, Homerin M, Hmissi A, Cassidy J, Boni C, Cortes-Funes H, Cervantes A, Freyer G, Papamichael D, Le Bail N, Louvet C, Hendler D, de Braud F, Wilson C, Morvan F, Bonetti A (2000) Leucovorin and fluorouracil with or without oxaliplatin as first-line treatment in advanced colorectal cancer. J Clin Oncol 18(16): 2938-2947.

Fernandez-Martos C, Pericay C, Aparicio J, Safont M, Salud A, Massuti B, Alonso V, Vera R, Escudero P, Martin-Richard M, Bosch C, Maurel J (2014) Chemoradiation (CRT) followed by surgery and adjuvant capecitabine plus oxaliplatin (CAPOX) compared with induction CAPOX followed by concomitant CRT and surgery for locally advanced rectal cancer: Results of the Spanish GCR-3 randomized phase II trial after a median follow-up of 5 years. J Clin Oncol 32(suppl 3): abstr 383.

Fontana E, Pucci F, Camisa R, Bui S, Galdy S, Leonardi F, Negri FV, Anselmi E, Losardo PL, Roncoroni L, Dell'abate P, Crafa P, Cascinu S, Ardizzoni A (2013) Long-term results of preoperative 5-fluorouracil-oxaliplatin chemoradiation therapy in locally advanced rectal cancer. Anticancer Res 33(2): 725-730.

Fukuda M, Nakamura Y, Kinoshita A, Soejima Y, Yamaguchi H, Ikeda T, Izumikawa $\mathrm{K}$, Takatani $\mathrm{H}$, Soda $\mathrm{H}$, Hayashi $\mathrm{N}$, Tsukamoto $\mathrm{K}$, Oka M, Kohno S (2012) Phase II study of irinotecan and cisplatin with concurrent split-course radiotherapy in limited-disease small cell lung cancer. Cancer Chemother Pharmacol 70(5): 645-651.

Gasparini G, Torino F, Ueno T, Cascinu S, Troiani T, Ballestrero A, Berardi R, Shishido J, Yoshizawa A, Mori Y, Nagayama S, Morosini P, Toi M (2012) A phase II study of neoadjuvant bevacizumab plus capecitabine and concomitant radiotherapy in patients with locally advanced rectal cancer. Angiogenesis 15(1): 141-150.

Gerard JP, Azria D, Gourgou-Bourgade S, Martel-Laffay I, Hennequin C, Etienne PL, Vendrely V, Francois E, de La Roche G, Bouche O, Mirabel X, Denis B, Mineur L, Berdah JF, Mahe MA, Becouarn Y, Dupuis O, Lledo G, Montoto-Grillot C, Conroy T (2010) Comparison of two neoadjuvant chemoradiotherapy regimens for locally advanced rectal cancer: results of the phase III trial ACCORD 12/0405-Prodige 2. J Clin Oncol 28(10): 1638-1644.

Glynne-Jones R, Anyamene N, Moran B, Harrison M (2012) Neoadjuvant chemotherapy in MRI-staged high-risk rectal cancer in addition to or as an alternative to preoperative chemoradiation? Ann Oncol 23(10): 2517-2526.

Glynne-Jones R, Falk S, Maughan TS, Meadows HM, Sebag-Montefiore D (2007) A phase I/II study of irinotecan when added to 5-fluorouracil and leucovorin and pelvic radiation in locally advanced rectal cancer: a Colorectal Clinical Oncology Group Study. Br J Cancer 96(4): 551-558.

Gogna NK, Baxi S, Hickey B, Baumann K, Burmeister E, Holt T (2012) Split-course, high-dose palliative pelvic radiotherapy for locally progressive hormone-refractory prostate cancer. Int J Radiat Oncol Biol Phys 83(2): e205-e211.

Goldstein D, Mitchell P, Michael M, Beale P, Friedlander M, Zalcberg J, White S, Clarke S (2005) Australian experience of a modified schedule of FOLFOX with high activity and tolerability and improved convenience in untreated metastatic colorectal cancer patients. Br J Cancer 92(5): 832-837.

Hanly AM, Ryan EM, Rogers AC, McNamara DA, Madoff RD, Winter DC (2013) Multicenter Evaluation of Rectal cancer ReImaging pOst Neoadjuvant (MERRION) Therapy. Ann Surg 259(4): 723-727.

Hicks RJ (2005) The role of PET in monitoring therapy. Cancer Imaging $\mathbf{5}$ 51-57.

John M, Pajak T, Flam M, Hoffman J, Markoe A, Wolkov H, Paris K (1996) Dose escalation in chemoradiation for anal cancer: preliminary results of RTOG 92-08. Cancer J Sci Am 2(4): 205-211.

Loi S, Ngan SY, Hicks RJ, Mukesh B, Mitchell P, Michael M, Zalcberg J, Leong T, Lim-Joon D, Mackay J, Rischin D (2005) Oxaliplatin combined with infusional 5 -fluorouracil and concomitant radiotherapy in inoperable and metastatic rectal cancer: a phase I trial. Br J Cancer 92(4): 655-661.

Martin LK, Bekaii-Saab T (2013) Optimizing neoadjuvant therapy for rectal cancer with oxaliplatin. J Natl Compr Canc Netw 11(3): 298-307.

Metcalfe SK, Milano MT, Bylund K, Smudzin T, Rubin P, Chen Y (2010) Split-course palliative radiotherapy for advanced non-small cell lung cancer. J Thorac Oncol 5(2): 185-190.

Miszczyk L, Maciejewski B, Tukiendorf A, Wozniak G, Jochymek B, Gawryszuk A, Szweda M (2014) Split-course accelerated, hyperfractionated irradiation (CHA-CHA) as a sole treatment for advanced head and neck cancer patients - final results of randomized clinical trial. Br J Radiol 87(1041): 20140212.

Nakamura T, Yamashita K, Sato T, Ema A, Naito M, Watanabe M (2014) Neoadjuvant chemoradiation therapy using concurrent s-1 and irinotecan in rectal cancer: impact on long-term clinical outcomes and prognostic factors. Int J Radiat Oncol Biol Phys 89(3): 547-555.

O'Connell MJ, Martenson JA, Wieand HS, Krook JE, Macdonald JS, Haller DG, Mayer RJ, Gunderson LL, Rich TA (1994) Improving adjuvant therapy for rectal cancer by combining protracted-infusion fluorouracil with radiation therapy after curative surgery. N Engl J Med 331(8): 502-507.

Patel UB, Blomqvist LK, Taylor F, George C, Guthrie A, Bees N, Brown G (2012a) MRI after treatment of locally advanced rectal cancer: how to 
report tumor response-the MERCURY experience. AJR Am J Roentgenol 199(4): W486-W495.

Patel UB, Brown G, Rutten H, West N, Sebag-Montefiore D, Glynne-Jones R, Rullier E, Peeters M, Van Cutsem E, Ricci S, Van de Velde C, Kjell P, Quirke P (2012b) Comparison of magnetic resonance imaging and histopathological response to chemoradiotherapy in locally advanced rectal cancer. Ann Surg Oncol 19(9): 2842-2852.

Pedersen D, Bentzen SM, Overgaard J (1994) Continuous or split-course combined external and intracavitary radiotherapy of locally advanced carcinoma of the uterine cervix. Acta Oncol 33(5): 547-555.

Pradier O, Christiansen H, Ambrosch P, Kron M, Schmidberger H, Hess CF (2004) A long-term follow-up study after split-course irradiation with concurrent chemotherapy (carboplatin) for locally advanced head and neck cancer and a review of the literature. ORL J Otorhinolaryngol Relat Spec 66(6): 325-331.

Ritter MA (1999) Determination of tumor kinetics: strategies for the delivery of radiotherapy and chemotherapy. Curr Opin Oncol 11(3): 177-182.

Rodel C, Liersch T, Becker H, Fietkau R, Hohenberger W, Hothorn T, Graeven U, Arnold D, Lang-Welzenbach M, Raab HR, Sulberg H, Wittekind C, Potapov S, Staib L, Hess C, Weigang-Kohler K, Grabenbauer GG, Hoffmanns H, Lindemann F, Schlenska-Lange A, Folprecht G, Sauer R (2012) Preoperative chemoradiotherapy and postoperative chemotherapy with fluorouracil and oxaliplatin versus fluorouracil alone in locally advanced rectal cancer: initial results of the German CAO/ARO/AIO-04 randomised phase 3 trial. Lancet Oncol 13(7): 679-687.

Roh MS, Yothers GA, O'Connell MJ, Beart RW, Pitot HC, Sheilds AF, Allegra CJ, Petrelli NJ, Landry JC, Ryan DP, Arora A, Evans TL, Soori GS, Chu L, Landes RV, Mohiuddin M, Lopa S, Wolmark N (2011) The impact of capecitabine and oxaliplatin in the preoperative multimodality treatment in patients with carcinoma of the rectum: NSABP R04. J Clin Oncol 29(Suppl 18): Abstr 3503.

Schmoll H-J, Haustermans K, Price TJ, Nordlinger B, Hofheinz R, Daisne J-F, Janssens J, Brenner B, Schmidt P, Reinel H, Hollerbach S, Caca K, Fauth WB, Hannig C, Zalcberg JR, Tebbutt NC, Mauer ME, Messina CGM, Lutz MP, Cutsem EV (2013) Preoperative chemoradiotherapy and postoperative chemotherapy with capecitabine and oxaliplatin versus capecitabine alone in locally advanced rectal cancer: First results of the PETACC-6 randomized phase III trial. J Clin Oncol 31: abstr 3531.

Shin SJ, Yoon HI, Kim NK, Lee KY, Min BS, Ahn JB, Keum KC, Koom WS (2011) Upfront systemic chemotherapy and preoperative short-course radiotherapy with delayed surgery for locally advanced rectal cancer with distant metastases. Radiat Oncol 6: 99.
Stelzner S, Hellmich G, Jackisch T, Ludwig K, Witzigmann H (2008) Selective surgical treatment of patients with rectal carcinoma and unresectable synchronous metastases based on response to preoperative chemotherapy. J Gastrointest Surg 12(7): 1246-1250.

Suarez J, Amat I, Vera R, Balen E, Gomez M, Lera JM (2011) Pathologic response of primary rectal cancer to oxaliplatin-based chemotherapy. Clin Colon Rectal Surg 24(2): 119-124.

Tarnawski R, Fowler J, Skladowski K, Swierniak A, Suwinski R, Maciejewski B, Wygoda A (2002) How fast is repopulation of tumor cells during the treatment gap? Int J Radiat Oncol Biol Phys 54(1): 229-236.

Therasse P, Arbuck SG, Eisenhauer EA, Wanders J, Kaplan RS, Rubinstein L, Verweij J, Van Glabbeke M, van Oosterom AT, Christian MC, Gwyther SG (2000) New guidelines to evaluate the response to treatment in solid tumors. European Organization for Research and Treatment of Cancer, National Cancer Institute of the United States, National Cancer Institute of Canada. J Natl Cancer Inst 92(3): 205-216.

van der Paardt MP, Zagers MB, Beets-Tan RG, Stoker J, Bipat S (2013) Patients who undergo preoperative chemoradiotherapy for locally advanced rectal cancer restaged by using diagnostic MR imaging: a systematic review and meta-analysis. Radiology 269(1): 101-112.

van Dijk TH, Tamas K, Beukema JC, Beets GL, Gelderblom AJ, de Jong KP, Nagtegaal ID, Rutten HJ, van de Velde CJ, Wiggers T, Hospers GA, Havenga K (2013) Evaluation of short-course radiotherapy followed by neoadjuvant bevacizumab, capecitabine, and oxaliplatin and subsequent radical surgical treatment in primary stage IV rectal cancer. Ann Oncol 24(7): 1762-1769.

Yeung JM, Kalff V, Hicks RJ, Drummond E, Link E, Taouk Y, Michael M, Ngan S, Lynch AC, Heriot AG (2011) Metabolic response of rectal cancer assessed by 18-FDG PET following chemoradiotherapy is prognostic for patient outcome. Dis Colon Rectum 54(5): 518-525.

Young H, Baum R, Cremerius U, Herholz K, Hoekstra O, Lammertsma AA, Pruim J, Price P (1999) Measurement of clinical and subclinical tumour response using $[18 \mathrm{~F}]$-fluorodeoxyglucose and positron emission tomography: review and 1999 EORTC recommendations. European Organization for Research and Treatment of Cancer (EORTC) PET Study Group. Eur J Cancer 35(13): 1773-1782.

This work is published under the standard license to publish agreement. After 12 months the work will become freely available and the license terms will switch to a Creative Commons AttributionNonCommercial-Share Alike 3.0 Unported License. 